\title{
ERRATUM
}

Christopher R. J. Charles • Zeina S. Khan

Stephen W. Morris

\section{Pattern scaling in axial segregation}

How does the wavelength of axial segregation scale with the tube diameter?

Published online: 8 March 2006

C) Springer-Verlag 2006

\section{Granular Matter (2006) DOI: 10.1007/s10035-005-0208-z}

Due to a productional error, in the original publication of this article, there was a typographical mistake in the Abstract. The first sentence should read: "Granular mixtures frequently segregate by grain size along the axis of partially-filled, horizontal, rotating tubes."

The online version of the original article can be found at http://dx.doi.org/10.1007/s10035-005-0208-z

C.R.J. Charles · Z.S. Khan · S.W. Morris $(\varangle)$

Department of Geology, University of Toronto,

22 Russell St., Toronto, Ontario, Canada, M5S 1A7

E-mail: christopher.charles@utoronto.ca

E-mail: zkhan@physics.utoronto.ca

E-mail: smorris@physics.utoronto.ca 